\title{
Achievements and futures of immune checkpoint inhibitors in non-small cell lung cancer
}

\author{
Zhenbin Qiu ${ }^{\dagger}$, Zihao Chen ${ }^{\dagger}$, Chao Zhang and Wenzhao Zhong ${ }^{*}$
}

\begin{abstract}
Non-small cell lung cancer (NSCLC) has been threatening human health for years. Cytotoxicity-based chemotherapy seems to reach plateau in NSCLC treatment. Immunotherapy with immune checkpoint inhibitors (ICIs) against programmed cell death 1 (PD-1/L1) axis are to provide long-term survival benefits for wild-type advanced NSCLC patients with acceptable adverse effects. Though beneficiary population is limited from monotherapy, combination strategies are expanding indicators. Retrospective evidences suggested ICls are also potentially useful for brain metastasis. Furthermore, the combination of ICls and surgery are to prolong progression free survival time for local advanced patients. Additionally, novel agents targeting in immune checkpoints other than PD-1/L1 demonstrated potential values in anticancer immunity. Herein, we summarize the novel therapies of checkpoint inhibitors in NSCLC treatment and some other potential immunotherapy to provide a conspectus for novel immunotherapy in NSCLC and perspective for the future in anti-cancer treatment.
\end{abstract}

Keywords: Checkpoint inhibitors, NSCLC, Novel therapies

\section{Background}

Lung cancer is the leading cause of cancer related death worldwide, including about $85 \%$ non-small cell lung cancer (NSCLC) [1]. Platinum-based chemotherapy had long been standard treatment for advanced NSCLC, with only about 7.9 months median overall survival (OS) [2]. Target therapy has already reformed the treatment of NSCLC harboring driver oncogene mutation, which significantly prolong the survival time [3]. Meanwhile, the progression of immunotherapy in recent years has also greatly promoted the treatment of driving gene negative NSCLC, with longer survival and miner adverse reaction than chemotherapy [4].

To our knowledge, through eliminating mutated cell, cytotoxic $\mathrm{T}$ lymphocyte (CTL) can prevent cancer's development and progression [5]. CTL's function is

\footnotetext{
*Correspondence: 13609777314@163.com

†Zhenbin Qiu and Zihao Chen contributed equally to this work

Guangdong Lung Cancer Institute, Guangdong Provincial Key Laboratory of Translational Medicine in Lung Cancer, Guangdong Provincial People's Hospital, Guangdong Academy of Medical Sciences, No. 106, Zhongshan Er Road, Yuexiu District, Guangzhou 510080, Guangdong, China
}

regulated by complicated immune signal pathways [6]. In cancer immunity, T cell receptor (TCR) recognizes major histocompatibility complex (MHC) with cancer-specific antigen as first signal to activate CTLs. And the second signal is from costimulatory factors, also called immune checkpoints, including stimulators for maintaining activation and inhibitors for preventing over-activation. For example, programed cell death-1 (PD-1) is such kind of inhibitor, which expressed in activated CTLs. Once PD-1 binds to its ligand, programed cell death ligand 1 (PD-L1) highly expressed in tumor cell's (TC) membrane, CTL's recognition to TCs would be suppressed, so that TCs could achieve self-adaption and escape from immune elimination [7]. Accordingly, immune checkpoint inhibitors (ICIs) can block that kind of pathways and rebuild the CTL's ability to clear malignant cells.

Efficacy of ICIs, targeting in PD-1/PD-L1 axis, in NSCLC's clinical treatment has been proved a lot, from second line to first line, even in early stage patients [8-12]. Long-term follow-up data demonstrated immunotherapy has great potential for long-term response [13]. However, limited beneficiary population and drug 
resistance are hindering the further development of immunotherapy [14]. With deeper research on anticancer immunity, novel immune checkpoint inhibitors are desired to expand beneficiary population from immunotherapy [15-18]. Herein, we summarize the novel therapies of checkpoint inhibitors in NSCLC treatment and some other potential immunotherapy to provide a conspectus for novel immunotherapy in NSCLC and perspective for the future in anti-cancer treatment.

\section{Immune checkpoint inhibitors in advanced NSCLC Pembrolizumab, nivolumab and atezolizumab}

Immune checkpoint inhibitors have made a great progression in advanced NSCLC without positive driver mutation in recent years [8-12]. The efficacy of single agent therapy with ICIs is proved from second line to first line. Due to the efficacy and safety demonstrated by pembrolizumab in keynote 001 [9], FDA approved it as an optional second-line treatment for advanced NSCLC. Subsequently, keynote 010 further proved that compared with docetaxel, PD-L1 positive (tumor proportion score, $\mathrm{TPS} \geq 1 \%$ ) patients could gain significantly survival benefits from pembrolizumab, especially those with TPS $\geq 50 \%$, and the incidence of adverse reactions was lower [10]. Moreover, results of keynote 024 and 042 supports the use of pembrolizumab monotherapy as first line treatment for PD-L1 positive NSCLC patients, especially for high expression population $[19,20]$. Despite lacking evidence of benefits from first line treatment, patients can also obtain survival and life quality benefits from monotherapy with nivolumab or atezolizumab after failing in first line treatment because of the positive results of checkmate 017/057 and OAK $[11,12]$ (Table 1).

Though single agent therapy with ICIs has already reformed the treatment strategy of advanced NSCLC, there is still a great proportion of patients could not respond [21]. Combination strategies may help to overcome the resistance (Table 2).

It is reported that platinum-based chemotherapy can contribute to sensitization of tumor to ICIs through increasing CD8+ T cell infiltration [22]. Keynote 021 is the first trial which succeed in combining platinumbased chemotherapy and ICIs for treat naïve pannegative advanced NSCLC [23]. Regardless of PD-L1's expression, the ORR is almost double in pembrolizumab plus chemotherapy comparing to chemotherapy, while the risks of progression and death are decreasing to only a half with the toxicity safely controlled. After that, keynote 189 and 407 successively announced their similar results in squamous and non-squamous cell carcinoma [24, 25], which have further strengthened evidences for combining ICIs and platinum-based chemotherapy as first line treatment. Comparing with keynote $024 / 042$, for patients with low or negative PD-L1 expression (TPS $<50 \%$ ), the strategy of combination with chemotherapy is safer and more cost-effective [26]. Additionally, Impower 131 and 132 reached their primary endpoint, proving that patients can gain more survival benefits and less risks from the combination of atezolizumab and chemotherapy rather than monotherapy with chemical agents $[27,28]$. Interestingly, in the exploring analysis, both trials are observed that in PD-L1 high expression and negative group, combination presents better PFS than monotherapy, while in PD-L1 low expression group, there is no significant difference between them, indicating the biomarkers for patient selection need to be explored more. After failed in the competition of monotherapy, exploring combination may help nivolumab to break the dilemma in first line treatment. In ASCO 2018 meeting, Borghaei et al. announced a sub-group analysis of checkmate 227, nivolumab plus chemotherapy has a trend in improving PFS comparing to chemotherapy in patients with negative PD-L1 expression ( $\mathrm{HR}=0.74$ [95\% CI 0.58 , 0.94]) [29]. Furthermore, nivolumab plus chemotherapy can significantly improve 1 -year PFS rate $(27 \%$ vs $8 \%$; $\mathrm{HR}=0.56[95 \% \mathrm{CI} 0.35,0.91])$ in those patients harboring high tumor mutation burden (TMB $\geq 10 \mathrm{Mut} / \mathrm{Mb}$ ) than chemotherapy, suggesting that high TMB is a good predictor for benefits of combination [29].

Cytotoxic T-lymphocyte association protein 4 (CTLA-4) is another negative immune checkpoint [7]. Differ to PD- 1 pathway, CTLA-4 pathway inhibits T cell in the initial stage of activation [30]. Thence, blocking both PD-1 and CTLA-4 pathways could make synergistic effects, which could awake more CTLs in the initial stage of immunity and recover the immune activity in the late stage. Ipilimumab is a human-IgG1 antibody targeting against CTLA-4. The combination of nivolumab and ipilimumab was evaluated in several trials. After efficacy and safety were confirmed in checkmate 012, checkmate 227 was initialed for exploring more evidences [31]. Regardless PD-L1's status, double ICIs can significantly improve ORR ( $45.3 \%$ vs $26.9 \%)$ and median PFS (7.2 $\mathrm{m}$ vs $5.4 \mathrm{~m}$ ) comparing to chemotherapy in high TMB group. It is worth mentioned that combination of two ICIs can achieve higher 1-year PFS ( $45 \%$ vs $27 \%$ ) than the combination of ICIs and chemotherapy in PD-L1 negative patients with high TMB. Safety is also satisfactory. $31.2 \%$ patients in combination group suffered from grade $3 / 4$ AEs, while $36.1 \%$ in chemotherapy group [32]. Furthermore, checkmate 568 recently confirmed that PD-L1 positive (TPS $\geq 1 \%$ ) and high TMB ( $\geq 10 \mathrm{Mut} / \mathrm{Mb})$ are both independent biomarkers for better effects prediction in such combination as first line treatment [33]. 


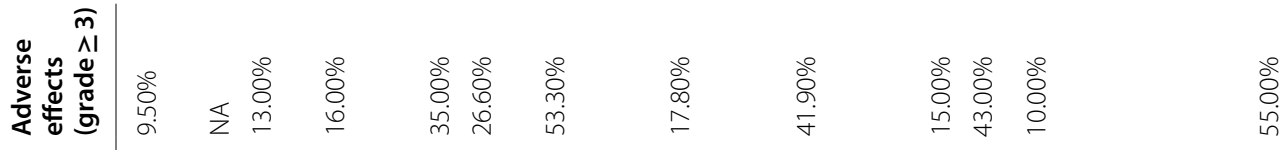

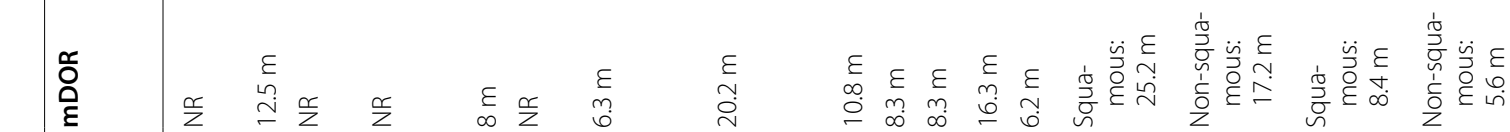

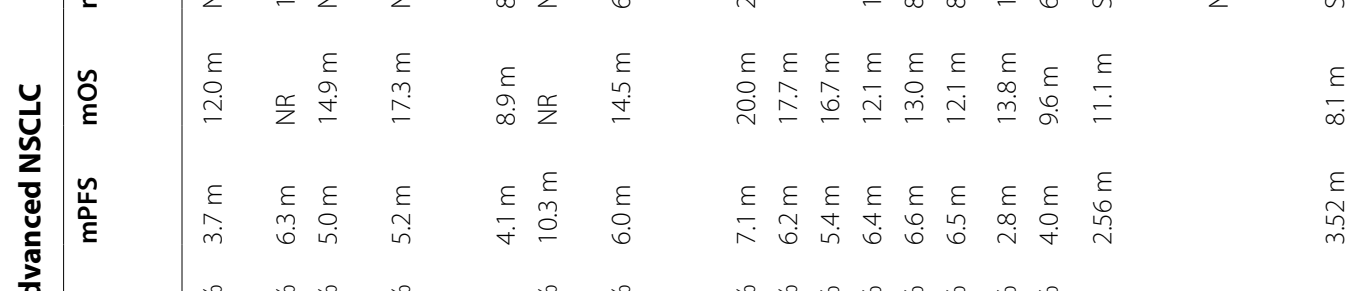

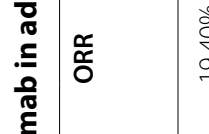

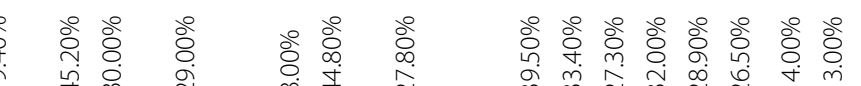

भे

ठें ठें ठें ठें

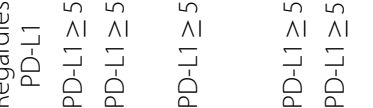

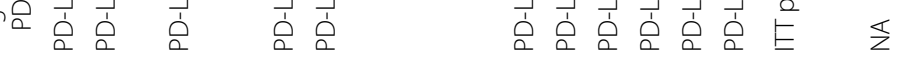
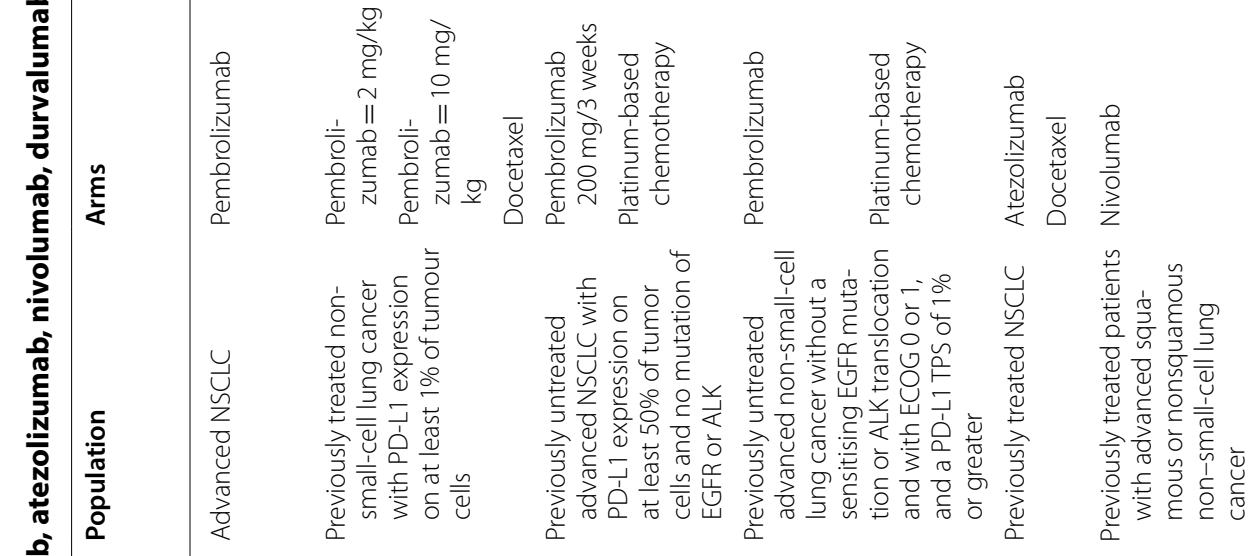

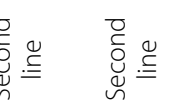

衰

竞

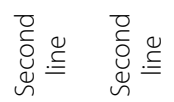

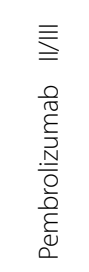

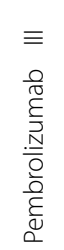

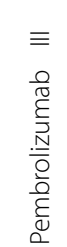



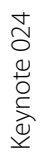

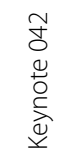

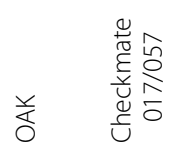

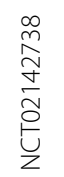

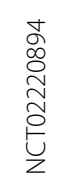

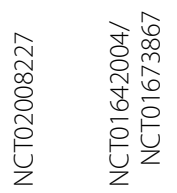




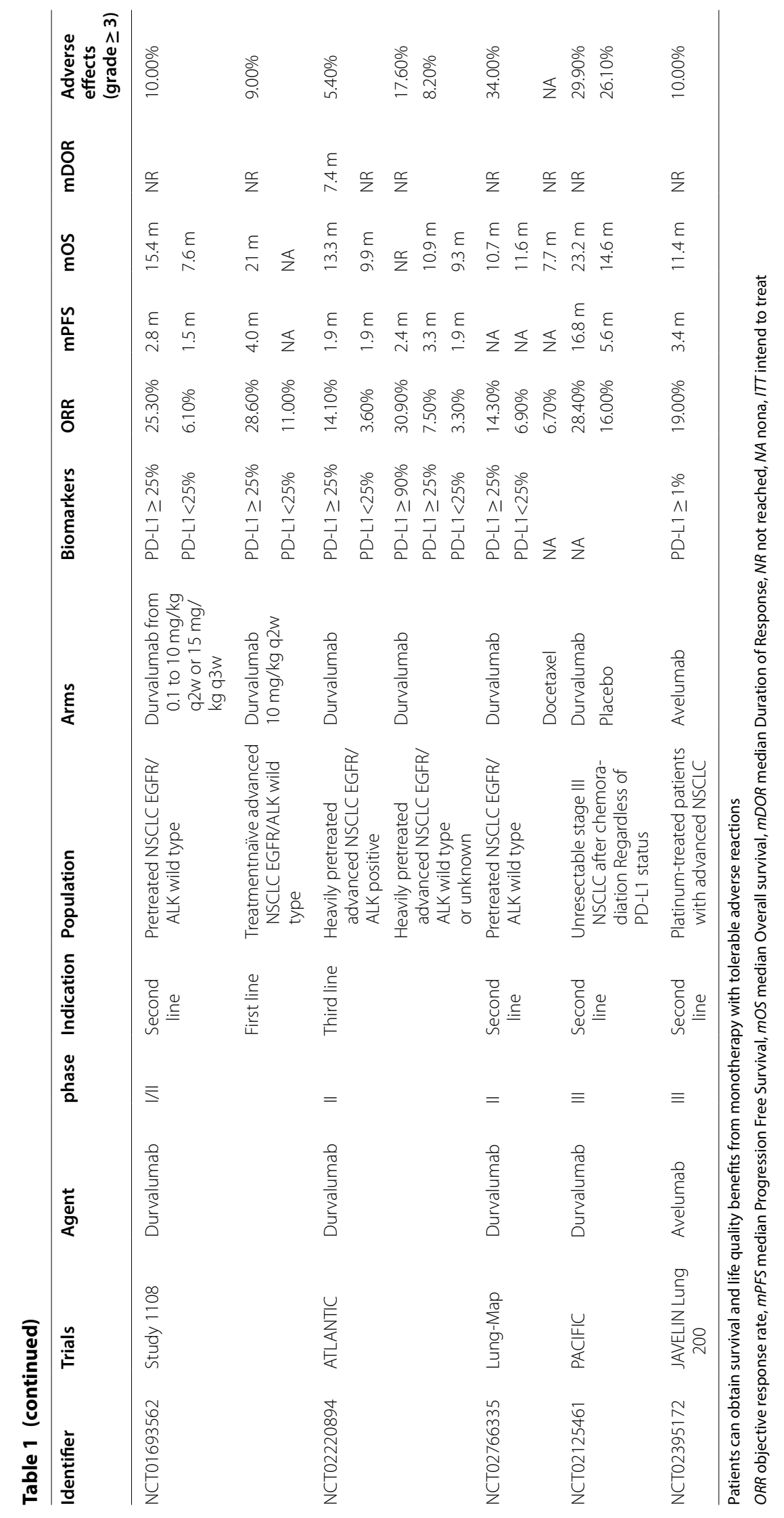




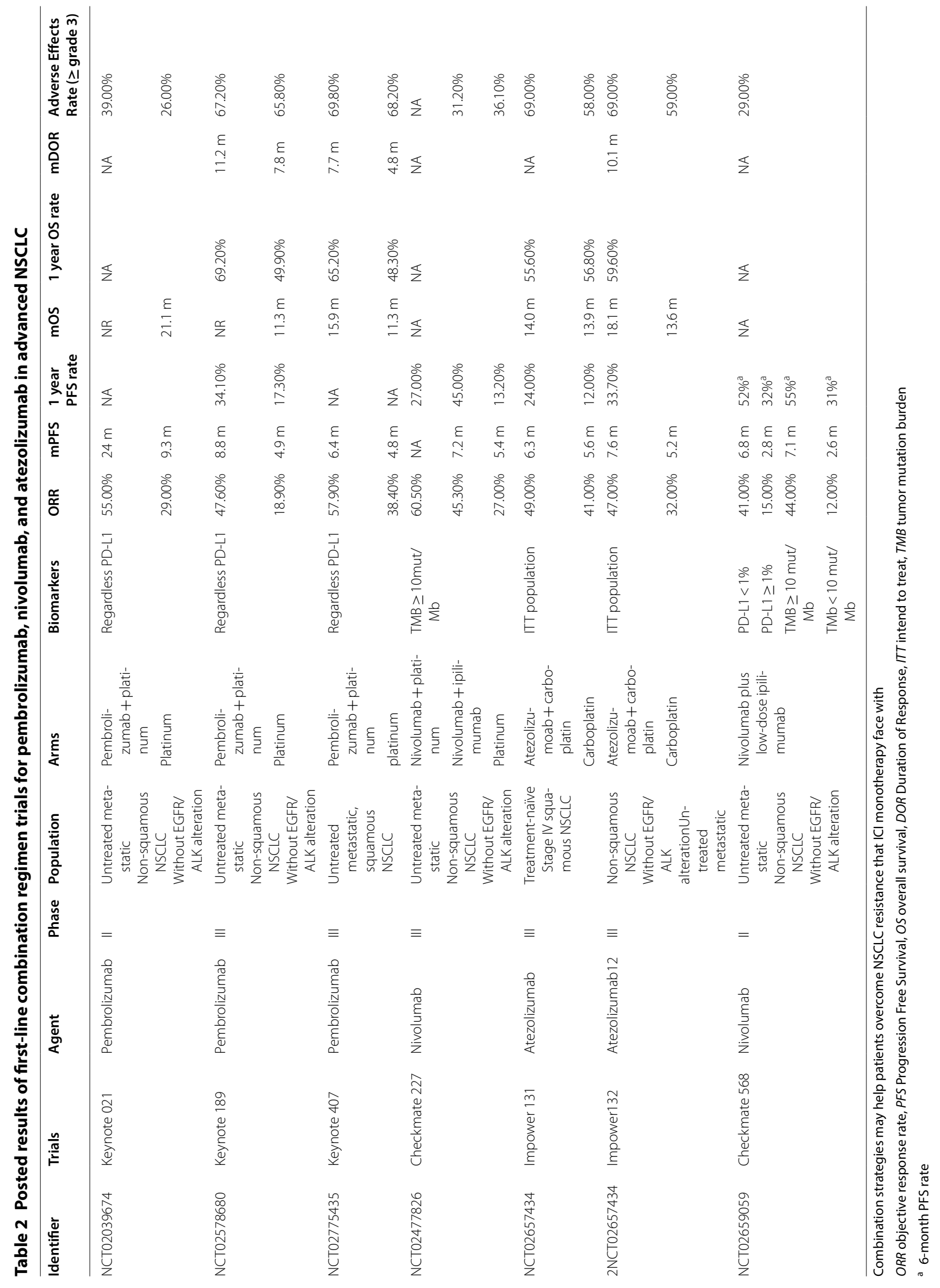




\section{Durvalumab and avelumab}

Durvalumab was first evaluated as a single agent in a large phase $1 / 2$ study in advanced solid tumor patients [34], including refractory advanced NSCLC (NCT01693562). According to prior lines of therapy, the ORR was $27.1 \%$ in treatment-naïve vs $18.8 \%$ in patients pretreated with platinum-based chemotherapy (second-line). High PD-L1 expression was associated with better response rates (25.3\%; 39/154 patients) compared to low PD-L1 expression patients $(6.1 \% ; 7 / 115$ patients). Antonia et al. [35], reported that according to the line of treatment, the ORR was $26.1 \%$ in high PD-L1 vs $4.2 \%$ in low PD-L1 in platinum-refractory patients, and $22.0 \%$ in high PD-L1 vs 6.1\% in low PD-L1 in third or later lines. S1400A LungMap umbrella phase 2 trial (NCT02766335) showed durvalumab having an ORR of $14.3 \%$ in $\geq 25 \%$ PD-L1 expression $(\mathrm{n}=14)$ and $6.9 \%$ in low/negative PD-L1 $(\mathrm{TPS} \leq 25 \%) \quad(\mathrm{n}=25) \quad$ [36]. ATLANTIC phase2 study (NCT02087423) showed PD-L1 expression $\geq 25 \%$ with a better median PFS than low/negative PD-L1 population (3.3 m vs $1.9 \mathrm{~m}$ ) [37]. In a heavily pretreated EGFR/ALK wild-type or unknown population, durvalumab demonstrated activity and durable responses. Trials of durvalumab combination regimens initiated, owing to the great success of durvalumab in second-line treatment as single agent. Avelumab is one of the last PD-L1 inhibitors to access the market, a fully human immunoglobulin G1 (IgG1) monoclonal antibody that specifically binds PDL1 and inhibits its binding to PD-1 [38]. JAVELIN Lung 200 is the first phase 3 trial of avelumab in patients with platinum pretreated NSCLC as monotherapy. Though median overall survival did not differ between avelumab and docetaxel group(11.4 $\mathrm{m}$ vs $10.3 \mathrm{~m}$ )in full analysis set population (FAS), post hoc analyses identified that specific populations who could benefit from anti-PD-1 or anti-PD-L1 antibodies. In PD-L1 population,median overall survival in subgroup TPS $\geq 80 \%$ and $\geq 50 \%$ was 17.1 months and 13.6 months in the avelumab group, comparing with 9.2 months in the docetaxel group [39]. These results indicate that most patients with high PD-L1 expression can achieve improved overall survival if given avelumab.

Durvalumab is currently being investigated in combination with different immunotherapies, in the majority of cases with tremelimumab. Durvalumab in combination with tremelimumab was initially assessed in a phase $1 / 2$ study (006, NCT02000947) in 102 treatment-naïve NSCLC patients [40]. Durvalumab demonstrated clinical activity with an ORR of $17 \%$ [95\% CI 9-29]). Based on the safety and activity, durvalumab $20 \mathrm{mg} / \mathrm{kg}$ q4w plus tremelimumab at $1 \mathrm{mg} / \mathrm{kg}$ were the recommended dose for phase 3 trials. The phase 3 MYSTIC trial (NCT02453282) enrolled 1092 advanced EGFR/ALK wild-type treatment-naïve NSCLC patients to compare durvalumab plus tremelimumab vs durvalumab vs $\mathrm{SoC}$ (platinum-based chemotherapy). In July 2017, MYSTIC trial did not meet the primary endpoint of PFS compared to chemotherapy. The study is continuing as planned to assess the primary endpoint of OS, PFS [41]. Classically, platinum-doublet chemotherapy has been the SoC as first-line therapy for advanced NSCLC, improving survival and quality of life in treatment-naïve patients. However, recently single agent PD-1 inhibitor demonstrated better outcomes compared to platinum-based chemotherapy in $\geq 50 \%$ PD-L1 tumors [42], as well as in combination with platinum-based chemotherapy for nonsquamous population, regardless of PD-L1 expression [23, 43]. Based on this potential synergism, several studies are currently evaluating ICI-chemotherapy combinations of durvalumab. For now, the limited evidence available is insufficient to establish the clinical impact of ICIs for EGFR and ALK-positive patients. The population harboring a driver molecular alteration such as an EGFR mutation is generally excluded from the majority of immunotherapy clinical trials. The only data available are derived from subgroup analyses from the phase 3 study with single-agent durvalumab in previously-treated populations, which showed no clear benefit in a small number of EGFR mutated patients [12, 42, 44], and with an insufficient basis to draw definite conclusions. The ALK positive population has also been widely excluded from the majority of immunotherapy clinical trials. Several ongoing studies are evaluating the safety and efficacy of different ICIs as a single agent or in combination with an ALK TKI, however no solid evidence has been reported to date [37]. In the phase $1 \mathrm{~b}$ TATTON study (NCT02143466) the combination durvalumab plus osimertinib was evaluated in EGFR-mutated patients. However, due to the high incidence of interstitial lung disease (ILD), this study arm was stopped prematurely, as was the phase 3 CAURAL trial (NCT02454933) assessing osimertinib plus durvalumab vs osimertinib in second-line EGFR-mut NSCLC patients. The phase II ATLANTIC trial testing durvalumab as third-line treatment included the largest cohort of EGFRmutant patients treated with ICI $(n=98)$ after progression on EGFR TKI and chemotherapy. According to PD-L1 expression $(<25 \%$ or $\geq 25 \%$ ), durvalumab achieved a RR of $3.6 \%$ and $14.1 \%$, a similar median PFS 1.9 months and a median OS of 9.9 months and 13.3 months, respectively. As the data showed, even patients with heavily pretreated, EGFR/ ALK mutation-positive advanced NSCLC may also benefit from greater than or equal to third-line PD-1/PD-L1 inhibitors treatment, with durable efficacy and a promising effect on OS. The most impressive results for immunotherapy and radiation, have come from the phase 3 
PACIFIC trial (NCT02125461). It showed positive results with durvalumab significantly reducing the risk of disease worsening or death for stage III unresectable lung cancer. Median PFS was 16.8 months with durvalumab vs 5.6 months with placebo. And ORR was $28.4 \%$ with durvalumab vs $16 \%$ with placebo $(p<0.001)$ [45]. The FDA approved durvalumab for the treatment of unresectable stage III NSCLC without progression after treatment with chemotherapy and radiation (chemoradiation) in 2018 [46]. Ongoing phase 3 trials will provide illuminating data to confirm the place of durvalumab in NSCLC patients (Table 3 ). Both as monotherapy and combination therapy in the JAVELIN Solid Tumor trial [38], avelumab showed a manageable safety profile and promising clinical activity in this population of pretreated metastatic or recurrent NSCLC patients. Regarding its tolerability profile, fatigue (25\%) and infusion-related reactions (19\%) were the most frequent grade $\geq 3$ adverse events. Despite the antitumor activity shown by avelumab in patients with advanced pretreated NSCLC patients, this novel anti-PD-L1 compound still has a long pathway to walk in order to demonstrate its potential clinical utility and own personality, for the first and second line scenario in advanced NSCLC. Ongoing studies will contribute to a better understanding of the efficacy and safety of avelumab (Table 4).

\section{Immune checkpoint inhibitor in NSCLC with CNS metastasis}

Central nerve system (CNS) metastasis is quite common in advanced NSCLC. And about $40 \%$ driver mutation negative patients would suffer from it [47]. Local treatment for CNSs locus has limited efficacy in survival time extension [48]. Systematic immunotherapy has been an important part for advanced NSCLC, but the efficacy in CNSs metastasis patients is still under exploring. A retrospective research conducted in Israel found that nivolumab can provide equal survival benefits for patients with or without CNS metastasis (median OS: $7.0 \mathrm{~m}$ vs $5.2, \mathrm{p}=0.5$ ) [49], which means both intracranial and extracranial lesions can benefit from ICIs. For pretreated, stable and asymptomatic CNS involved patients, atezolizumab and nivolumab seems to be good choices. In OAK trials, atezolizumab provided nearly double median OS than docetaxel for CNS involved patients (20.1 m vs 11.9 m, HR 0.54; 0.31-0.94 95\% CI) and longer median time to develop new CNS diseases (not reach vs $9.5 \mathrm{~m}$ ) [12]. In ASCO 2016, a sum-analysis of checkmate 017/057/063 revealed that nivolumab can prolong survival time ( $8.4 \mathrm{~m}$ vs $6.2 \mathrm{~m}$ ) with less irAEs comparing to docetaxel [50], and the similar results were achieved by EAP program with more cases in Italy [51]. Keynote 024 is a trial of first line treatment including CNS metastasis patients [20]. 18 patients with CNS metastasis harboring high PD-L1 (TPS $\geq 50 \%$ ) in pembrolizumab group have better PFS and OS data than the other 10 patients in chemotherapy. In a perspective phase 2 study for pembrolizumab including 18 stable brain metastasis patients with PD-L1 positive (TPS $\geq 1 \%$ ), the response rate among them is $33 \%$ [52], indicating the pembrolizumab is work for selected CNS related patients. Accordingly, though lacking enough perspective evidence, ICIs as monotherapy in advanced NSCLC with brain metastasis has been proved preliminarily.

Radiotherapy is standard local treatment for brain metastatic lesions. To our knowledge, radiation induced inflammatory can promote necrosis of tumor and tumorassociated antigen presented, and further activates $\mathrm{T}$-cell in anticancer immunity [53]. Thence, combination of immunotherapy and radiotherapy may play a synergistic role in advanced NSCLC therapy, which were improved by a secondary analysis of keynote 001 [54]. Herein, the question is whether the adding ICIs would help to add more benefits for CNS metastatic patients. In Pacific study, less new brain diseases were found in arm durvalumab (5.5\% vs $11.0 \%)$ [55], suggesting that combination of extracranial radiotherapy and ICIs would help to control brain metastasis. Chen et al. reported that patients with brain metastasis in melanoma, nephroma and NSCLC can have significant survival benefits from concurrent immunoradiotherapy comparing to radiotherapy alone or asynchronous immunoradiotherapy (median OS: $24.7 \mathrm{~m}$ vs $12.9 \mathrm{~m}$ vs $14.5 \mathrm{~m}$ ) [56]. In a retrospective research including 17 CNS related NSCLC patients, 48\% 6-month intracranial ORR was achieved [57]. However, efficacy is varied according to the order of radiation and ICIs. 57\% 6-month intracranial ORR was seen in patients who received radiation before or during immunotherapy while $0 \%$ in after, indicating processing radiotherapy before or during immunotherapy has better efficacy. Beside efficacy, safety is another important area needs to be explored in depth. Hubbeling HG et al. found that treatment with ICIs and brain radiation wouldn't improve incidence of radiation related adverse effects (AEs) significantly and no difference in AEs rate base on the order of treatment [58]. However, another retrospective analysis reported that taking ICIs as monotherapy after gamma knife will increase the risk of radionecrosis of intracranial lesion to $37.5 \%$ [59]. Thence, combination of immunotherapy and radiotherapy should be carefully selected. Herein, we are looking forward the perspective trails (NCT02978404, NCT02858869), which are conducting for exploring more evidences in the combination of immunotherapy and radiotherapy, to answer the questions in fractionation schedule, radiation dose, target volume and patient selection. More combination strategies 


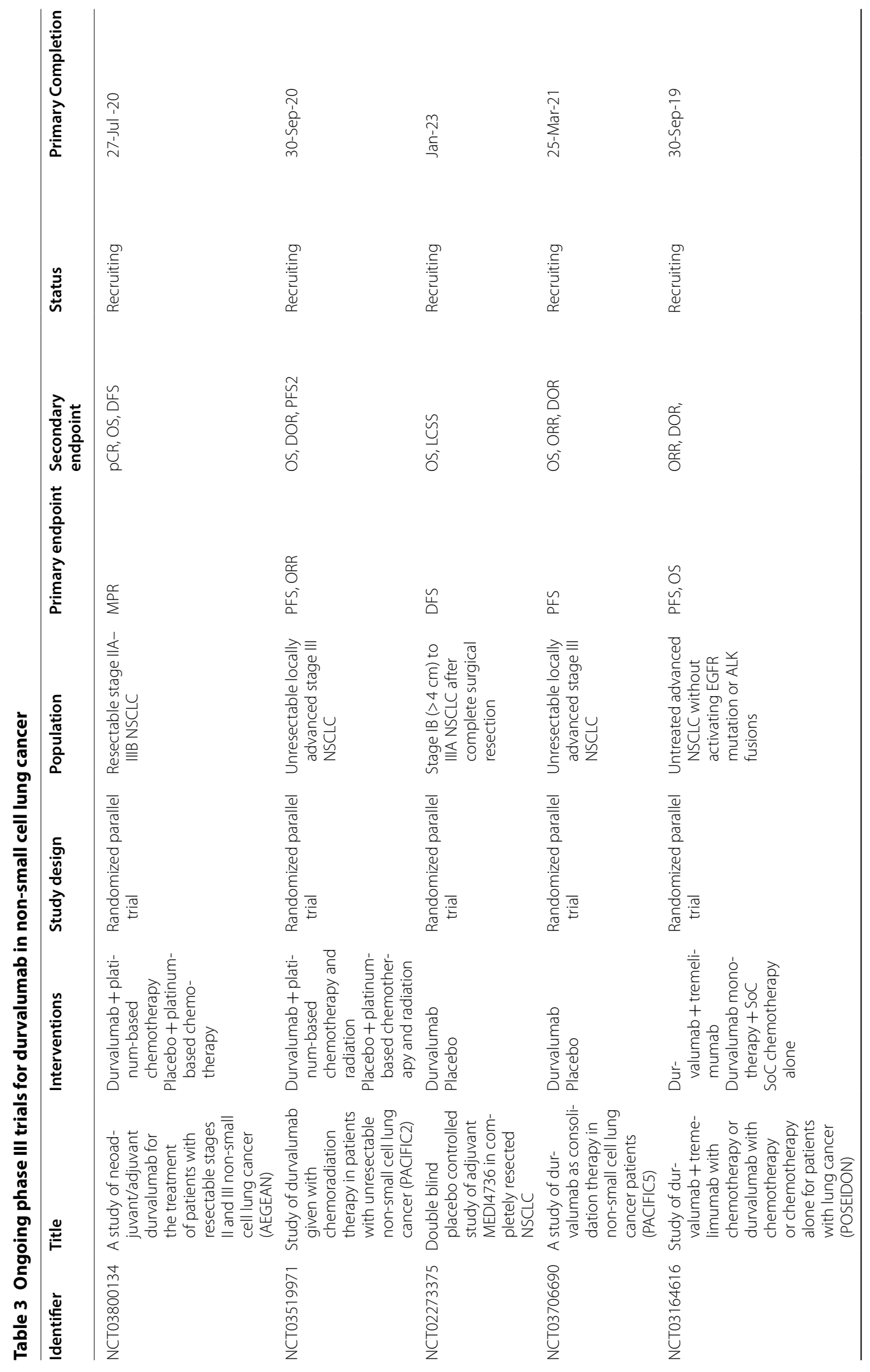




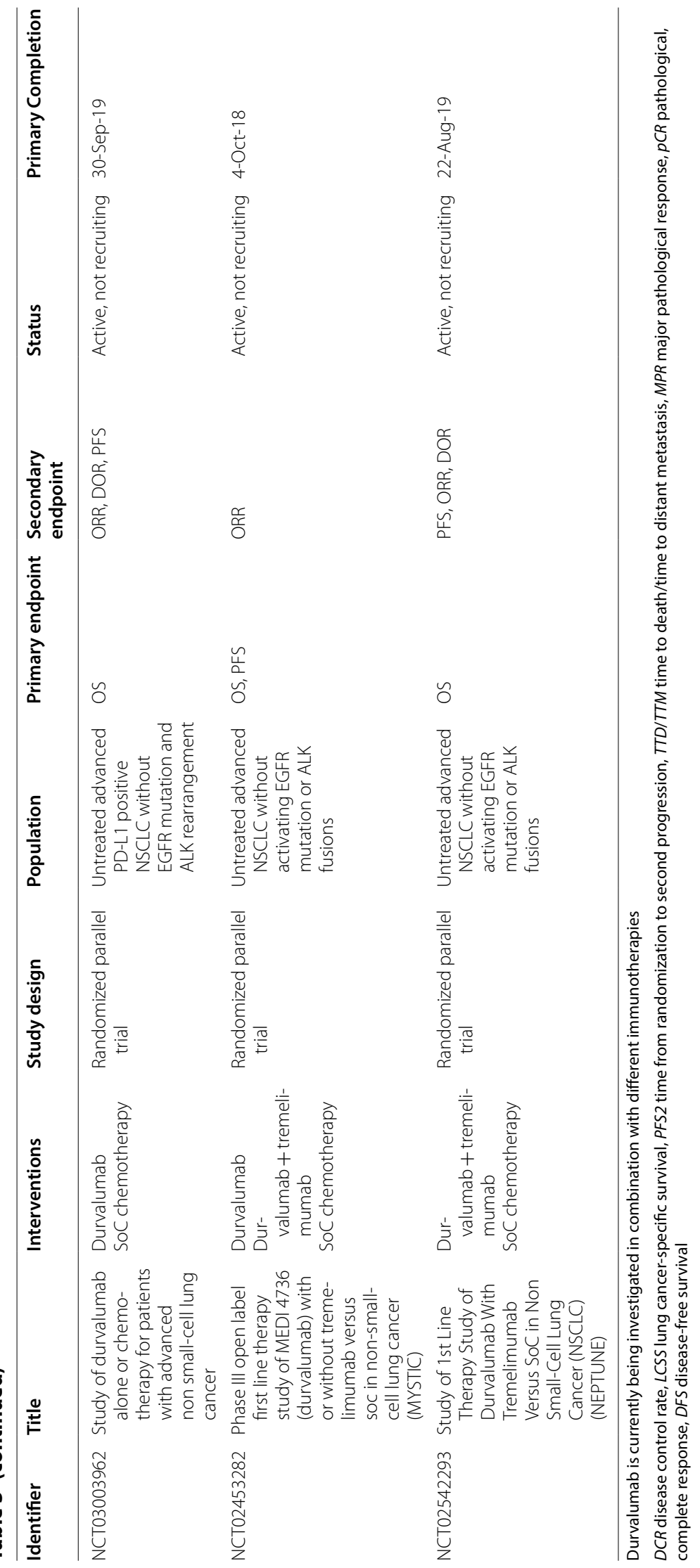




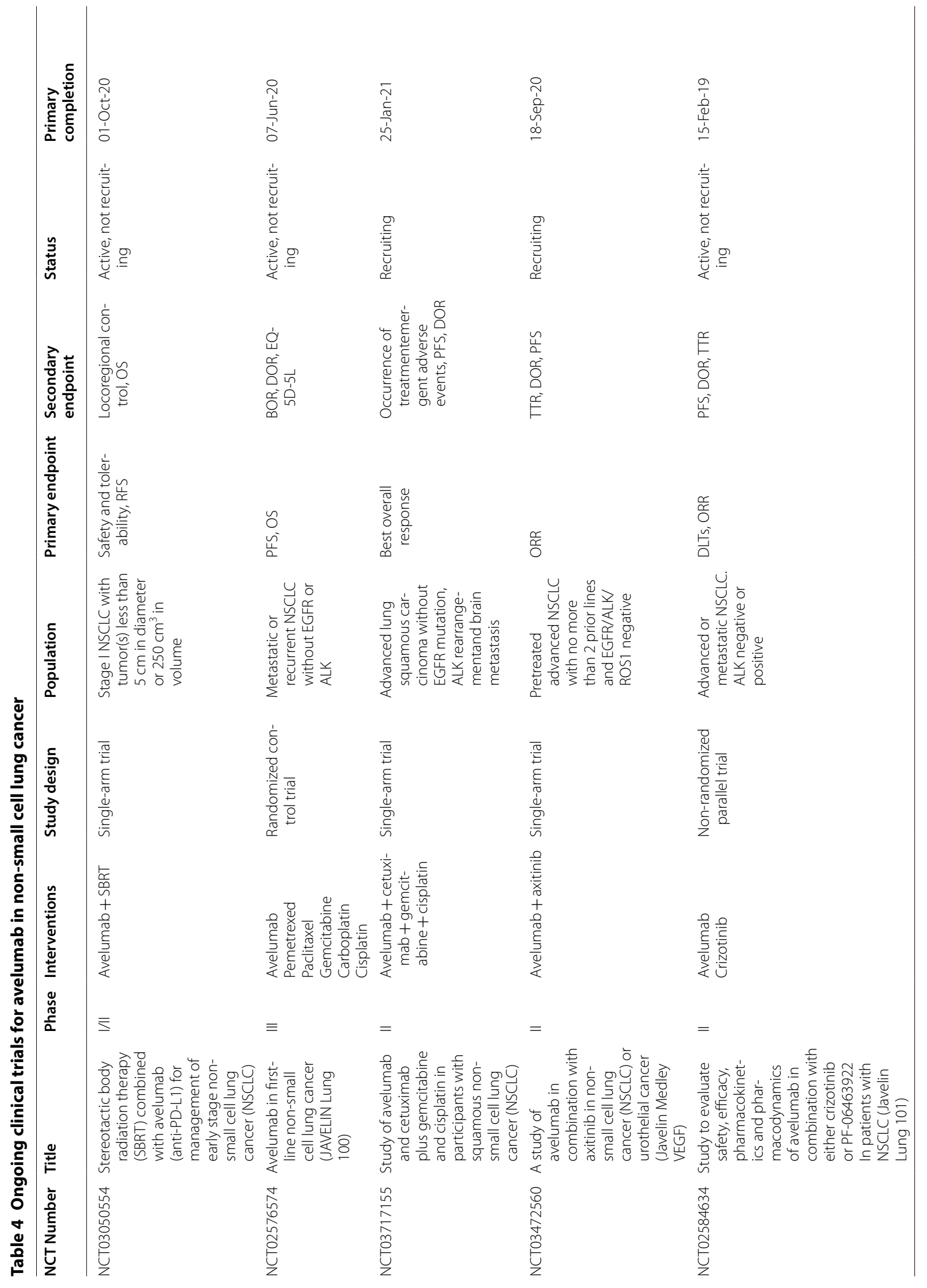




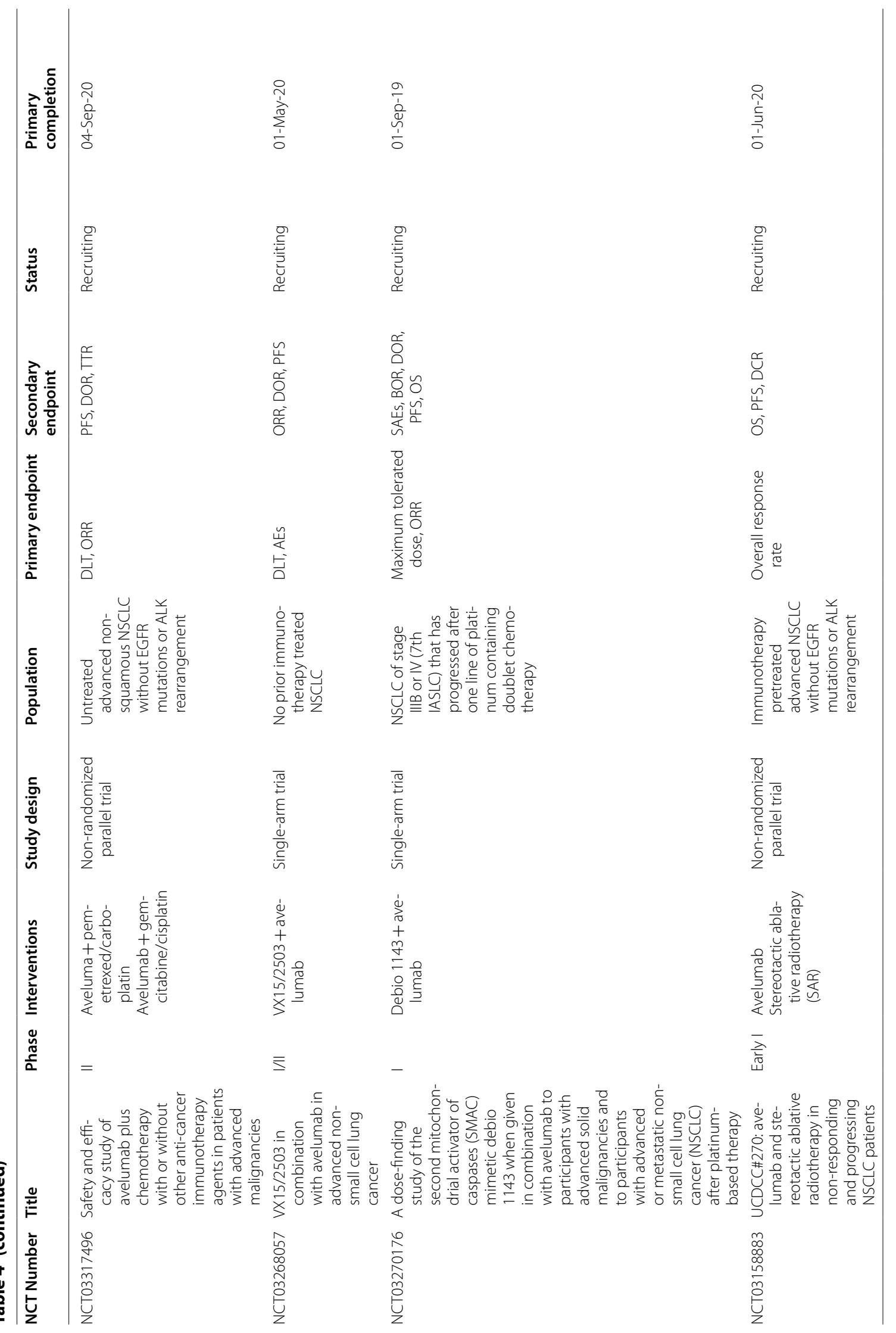




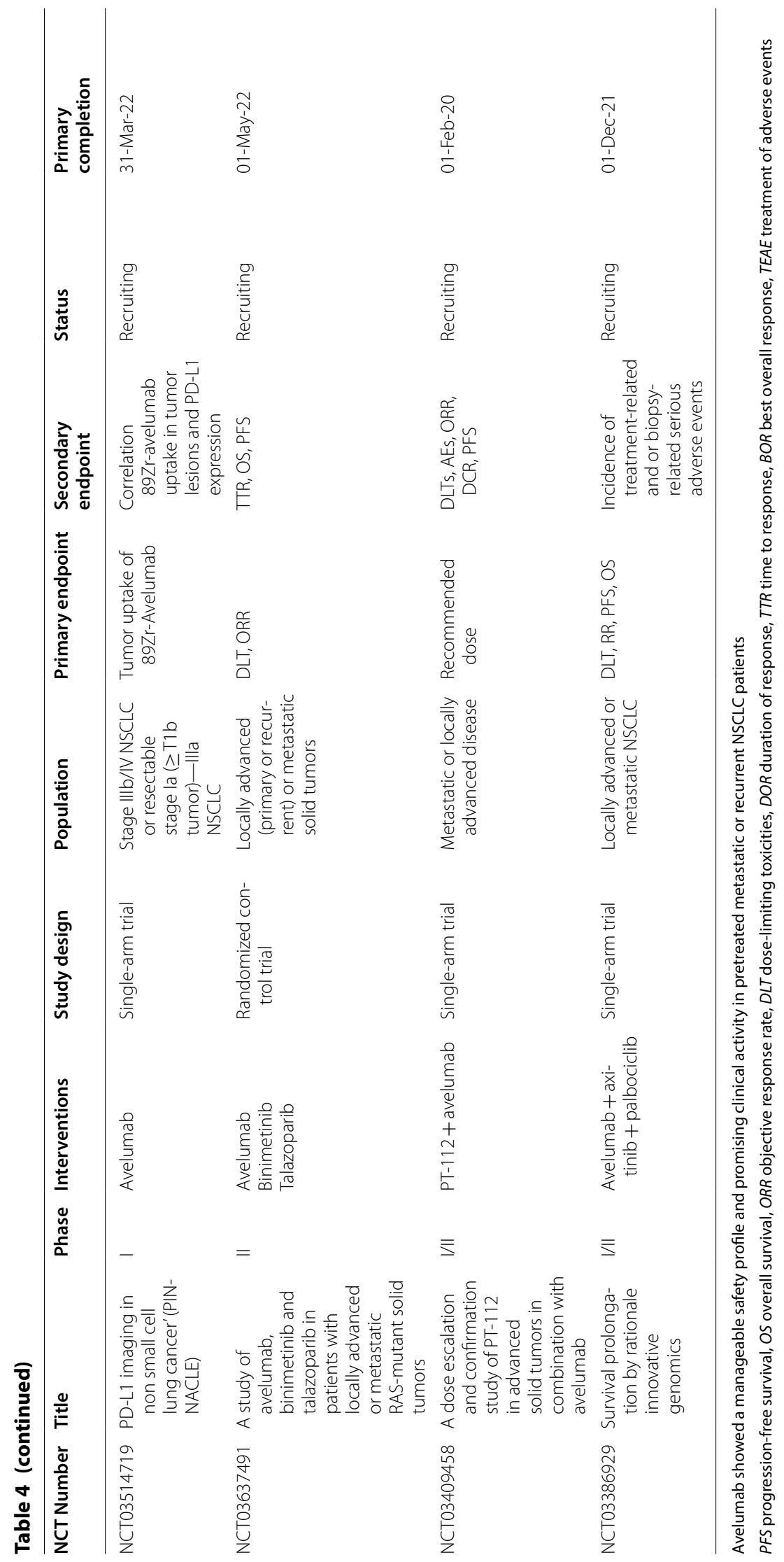


for ICIs and other therapies in advanced NSCLC with CNS metastasis are still under exploring. A sub-analysis of keynote 189 with 109 brain metastasis patients, combination of pembrolizumab and chemotherapy significantly extents OS comparing to monochemotherapy. NCT0296993 is a trail for exploring double ICIs plus radiotherapy and NCT02681549 is for combination of immunotherapy and bevacizumab (Table 5).

\section{Neoadjuvant immune checkpoint inhibitors in NSCLC}

Surgery is the only radical treatment strategy for resectable NSCLC currently [60]. However, 5-year survival rate after surgery is low, vary from 19 to $73 \%$ [61]. Theoretically, neoadjuvant therapy can eliminate micrometastatic diseases before surgery to reduce the rate of recurrence. However, preoperative chemotherapy could only increase 5\% survival benefits [62]. As for perioperative radiotherapy, it helps to improve local control rate, but seems to contribute nothing to survival benefits [63]. Immune checkpoint inhibitors have the opportunity break the bottleneck of current neoadjuvant therapy. Forde et al. firstly reported a pilot study of nivolumab as neoadjuvant therapy for stage II-IIIA NSCLC [8]. After taking 2 cycles nivolumab, 20/21 patients received operation, $45 \%$ (9/20 cases) major pathological response (MPR) was achieved with acceptable side-effect profile. Moreover, 15/20 patients are disease-free and alive for 30 months [64]. Tumor specific T-cell clones were observed in both resected samples and peripheral blood samples, indicating that ICIs can activate $\mathrm{T}$ cells systematically to eliminate both primary and metastatic tumors including micro-metastasis, which was more significant in MPR patients. Comparing to the expression of PD-L1, TMB is better for MPR prediction. Recently, an extended analysis of this study indicates that ctDNA and peripheral $\mathrm{T}$ cell expansion are potential biomarkers for response and surveillance prediction [64]. Interestingly, there is great disunity between pathologic and radiologic diagnosis in the evaluation of immune neoadjuvant therapy efficacy (RECIST: 2/20 PR, 18/20 SD; Pathology: 9/20 MPR), suggesting that current RECIST standard is not suitable for evaluation. The percentage change of standard uptake value (SUV) in positron-emission tomography scan (PET/CT) could be a better evaluation standard for neoadjuvant immunotherapy since it reflects the metabolic activity of cell, which is corresponded to pathological response [65]. According to the interim analysis of LCM3, atezolizumab is effective and safe as neoadjuvant therapy for stageIB to selected IIIB NSCLC patients [66]. Among 82 resected patients, 15 cases (18\%) achieved MPR with only $6 \%$ grade $3 / 4$ treatment related adverse effects occurred. Interestingly, biomarkers for
MPR prediction are quite different to Forde PM's study. MPR rate is not significantly different between PD-L1 negative and positive (cutoff: $1 \%$; clone sp142, $2 / 26$ vs $10 / 35, \mathrm{p}=0.055)$. However, it is meaningful in low and high expression (cutoff: TPS $=50 \%$; clone $22 \mathrm{c} 3,5 / 44$ vs $7 / 20, p=0.040)$. Moreover, median TMB (10.4 Mut/ $\mathrm{Mb})$ is not different in patients with MPR or not. Thus, patient selection for neoadjuvant immunotherapy is still controversial. Several ongoing trials are further exploring the dose, administration time, safety and efficacy of neoadjuvant ICIs for early stage NSCLC (LCM3 for atezolizumab, NEOSTAR for nivolumab, MK3475-223 for pembrolizumab).

Given the excellent synergistic effects of the combination of immunotherapy and other therapies in advanced NSCLC, several trials have been designed to evaluate the feasibility and safety of combination strategies in neoadjuvant therapy. Results of NADIM (NCT 03081689) presented in ASCO 2019 demonstrated that 41/46 stage IIIA patients were performed R0 resection after 3 cycles neoadjuvant immunochemotherapy (nivolumab + paclitaxel + carboplatin), 34 patients (83\%) achieved MPR including $24(71 \%)$ of them were complete pathologic response (pCR). Moreover, 90\% patients experienced downstaging [67]. MK-3475-671 is a double blind phase III study in comparing the efficacy of perioperative pembrolizumab or placebo plus platinum based neoadjuvant chemotherapy for stageIIB orIIIA NSCLC, which will answer the question whether patients can earn more benefits from adding ICIs in neoadjuvant chemotherapy. As we know from keynote-001, prior radiation would prolong PFS for patients received ICIs. Ongoing pilot trials NCT 03237377 is exploring the safety of neoadjuvant immunoradiotherapy for resectable IIIA NSCLC (durvalumab + radiation or durvalumab + termelimumab + radiation). Synergistic effect of ICIs-based combination in neoadjuvant therapy is another active research area. Data from NEOSTAR (ASCO 2019), higher median percentage of non-viable tumor (viable tumor: $20 \%$ vs $65 \%, \mathrm{p}=0.095)$ and of tissue residual memory TILs (CD3+:81.2\% vs $54.4 \%, \mathrm{p}=0.028$; $\mathrm{CD} 8+$ : $56.2 \%$ vs $38.3 \%, \mathrm{p}=0.069$ ) were seen in nivolumab plus ipilimumab group comparing to nivolumab alone [68]. Further analysis is still ongoing. Though efficacy and safety of combination strategies were preliminarily proved, patient selection is still unclear. Therefore, more studies are required to explore better biomarkers for patient selection of combination neoadjuvant therapy.

\section{Potential immune checkpoint inhibitors}

Though immune checkpoint inhibitors targeting in PD-1/L1 axis have achieved great progression in the treatment of NSCLC, the proportion of beneficiaries 


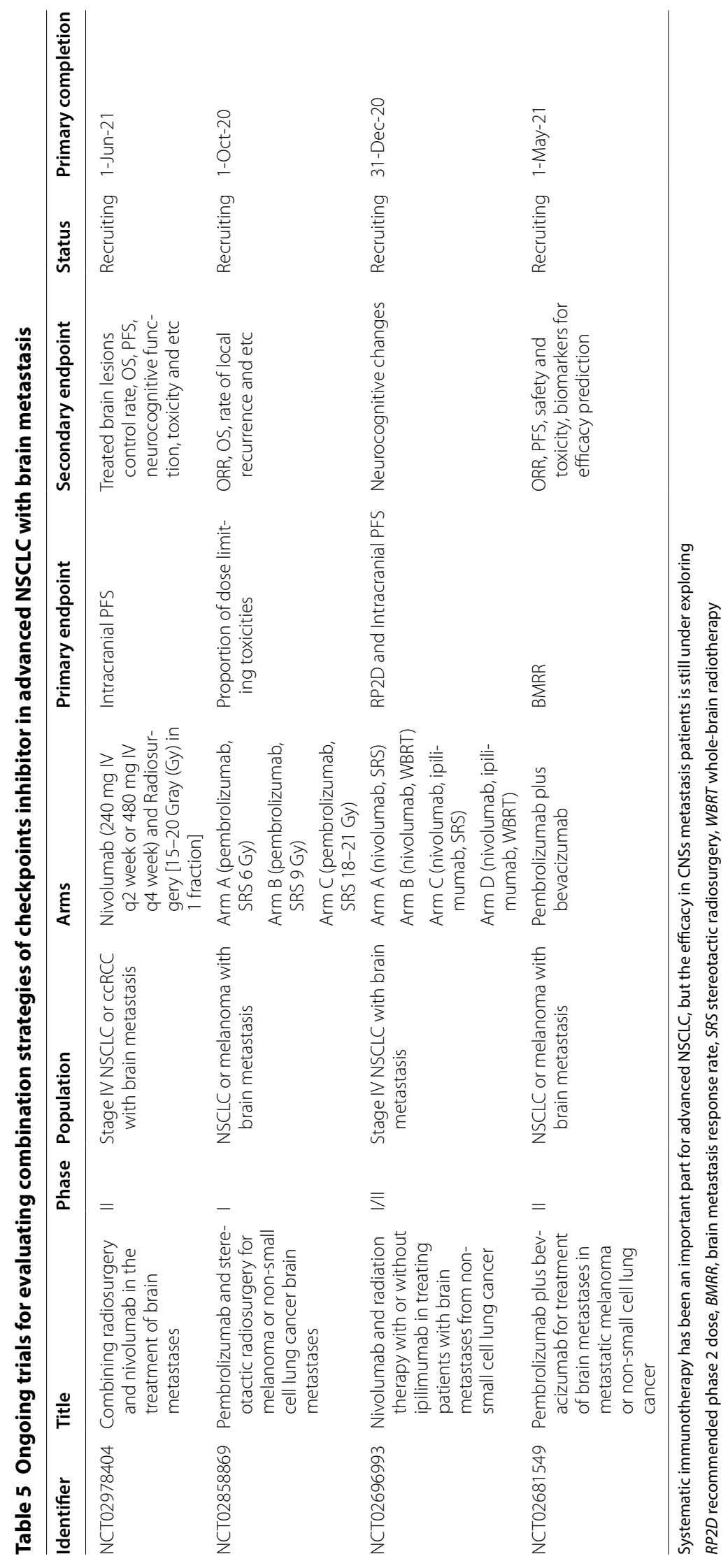




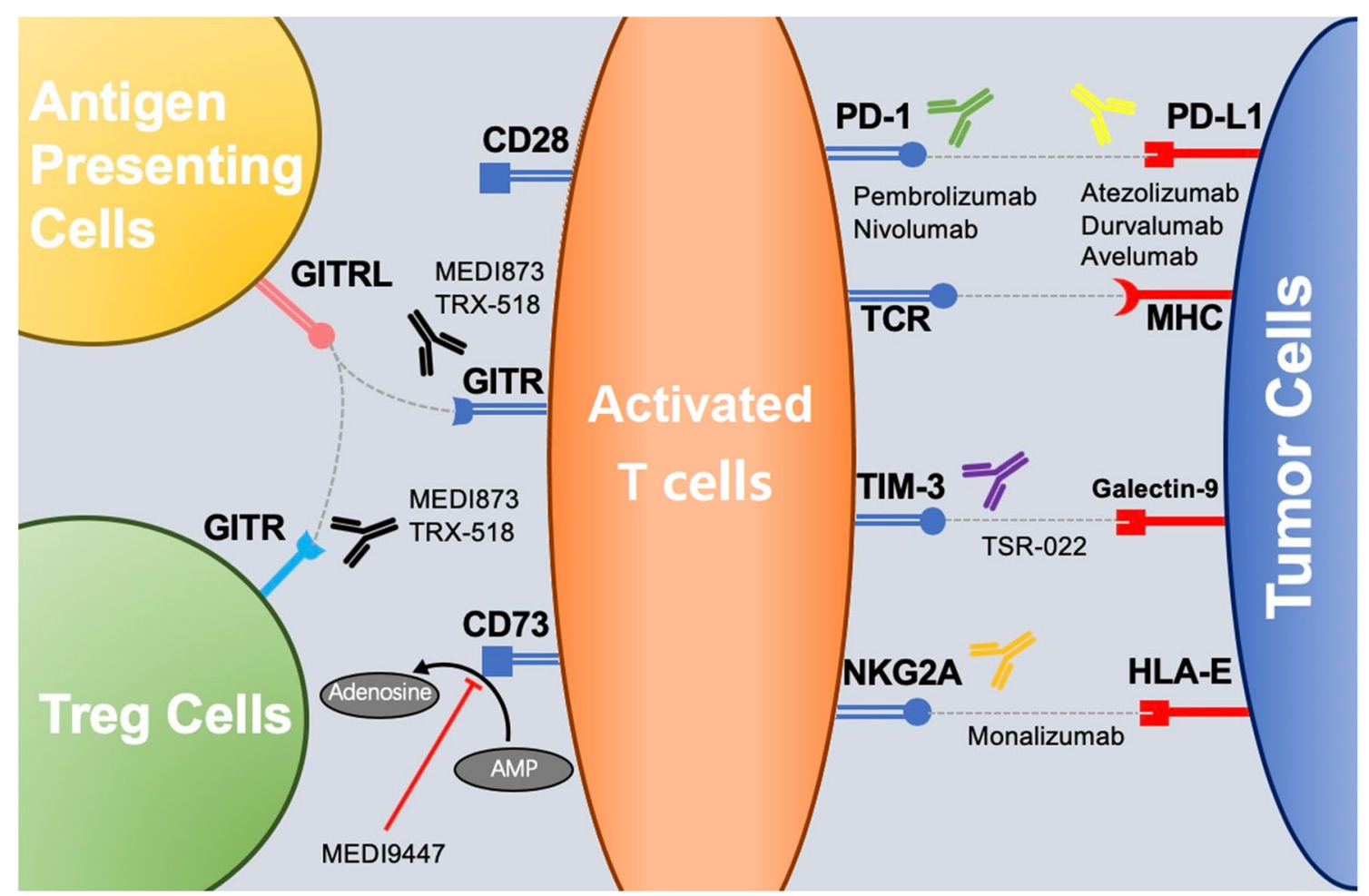

Fig. $1 \mathrm{Imm}$ me checkpoints with potential therapeutic value in NSCLC. Reported immune checkpoints inhibitors with therapeutic value in NSCLC are illustrated. Because of the limited beneficiary population and resistance to ICls against PD1/L1 axis, novel agents targeting in other immune checkpoints are developed to overcome the currently limitation of ICls. After the recognition of TCR and MHC, costimulatory factors help to regulate the activation of $T$ cells. The stimulation of positive checkpoints and inhibition of negative checkpoints are to maintain or recover the anticancer ability of T cells. Antibodies targeting negative checkpoints (PD-1/PD-L1, TIM-3/Galectin, NKG2A/HLA-E, CD73) are to release the inhibition of T cells, while agonists of positive checkpoints (GITR/GITRL) are to strengthen the activation of T cells

is still low currently [17]. Recent researches in other immune checkpoints are expected to expand the population benefiting from immunotherapy. NKG2A is an intracytoplasmic tyrosine-based inhibitor motif, expressed in NK cells and selectively in CD8+ CTLs in tumor microenvironment, which can block the immune ability of NK cell and CD8+ T cell if it binds its ligand (HLA-E) overexpressed in carcinoma of lung, cervix and head/neck [69]. Interestingly, anti-NKG2A antibodies can play anti-cancer role only in inflammatory tumor environment [17], indicating they need to be combined with other agents to kill tumor. Monalizumab is a humanized anti-NKG2A antibody, which can enhance the anti-tumor ability of NK cells, and can rebuild the anti-tumor ability of $\mathrm{CD} 8+\mathrm{T}$ cells when blocked with PD-1/PD-L1 axis at the same time. The preclinical study demonstrated that durvalumab alone can save about $40 \%$ mice from death, while combining with monalizumab can achieve an efficacy of $75 \%$ [17]. In addition, its efficacy and safety were evaluated in a phase II clinical trial of monalizumab and cetuximab in the treatment of recurrent squamous cell carcinoma of the head and neck. The mid-term analysis showed that the effect of dual drug combination was better than single drug of cetuximab, with an ORR of 31\% [69]. As for NSCLC, one arm of PIONeeR-Clinical study is exploring the efficacy of combination of durvalumab and monalizumab in advanced NSCLC resistance to ICIs. And the efficacy in neoadjuvant therapy for NSCLC is evaluating in NeoCOAST. Ecto-5'-nucleotidase (CD73) is an enzyme highly expressed in anergic $\mathrm{T}$ cell, which degenerates AMP to adenosine leading to inhibit CTLs function in anticancer immunity. Additionally, CD73 can induce angiogenesis and lymphangiogenic to promote the development and progression of tumor [16]. Therefore, antibody targeting in CD73 would inhibit the growth of cancer through reducing the production of adenosine to relieve its inhibitory function in CTLs and blocking angiogenesis and lymphangiogenic. Indeed, preclinical studies have demonstrated the anti-cancer abilities of anti-CD73 antibodies in several kinds of cancer. MEDI9447 (oleclumab) is a humanized anti-CD73 antibody [70]. Given the anticancer ability of oleclumab alone or in combination 
with durvalumab in vivo and animal model, a phaseIstudy (NCT02503774) is conducting for evaluating the safety, tolerability, pharmacokinetics, immunogenicity, and antitumor activity of MEDI9447 alone and in combination with durvalumab in adult subjects with select advanced solid tumors. However, since CD73 is involved in homeostasis regulation such as epithelial barrier function and intestinal secretion and reabsorption function, attention should be paid to the possible adverse effects when using CD73 [16].

Adaptive resistance to PD-1/L1 inhibitors is hampering the further progress of immunotherapy [14]. Koyama et al. reported that the selective activation of T-cell immunoglobulin mucin-3 (TIM3) is the key mechanism of resistance of anti-PD-1 immunotherapy [15]. Mice models (lung cancer) revealed that $\mathrm{CD} 8+\mathrm{T}$ cells would fail after anti-PD-1 resistance, which was related to the up-regulation of multiple immune checkpoints expression, especially TIM3. Furthermore, mice can earn more survival time from sequential blocking therapy with TIM3 after anti-PD-1 treatment than anti-PD-1 alone (11.9 weeks vs 5 weeks, $\mathrm{p}=0.0008$ ). Additionally, high levels of TIM3, rather than other immune markers, were detected in T cells of NSCLC patients who had been treated with anti-PD-1 and developed drug resistance. Therefore, inhibiting TIM3 would help to overcome the adaptive resistance to anti-PD-1. An interim analysis of AMBER study, posted in SITC 2018 meeting [71], revealed that for patients with advanced NSCLC after resistance to PD-1/L1 antibody, 9\% ORR was achieved by $100 \mathrm{mg}$ TSR-022 (anti-TIM3) combined with $500 \mathrm{mg}$ TSR-042 (anti-PD-1) and 15\% by each $300 \mathrm{mg}$, with acceptable adverse effects $(6.7 \%$ grade $\geq 3)$. It is worth mentioning that for those expressed more than $1 \%$ of PD-L1 in both groups, total ORR reached 33\%.

Great proportion of patients treated with single agents PD-1/L1 inhibitors could not develop durable anticancer response because of the inability to produce longterm immunological $\mathrm{T}$ cell memory. Current studies on costimulatory pathway demonstrated great potential to improve efficacy of checkpoint inhibition and induce durable anticancer response. GITR [glucocorticoidinduced tumor necrosis factor receptor (TNFR)-related protein] belongs to TNFR super family, which can activate anticancer ability of CD4+ and CD8+ $\mathrm{T}$ cells and block the inhibitor effect of Treg on CTLs [72]. Previous clinical studies revealed limited efficacy in monotherapy with agonists of GITF, but great potential value in combination of agonist of GITR and anti-PDI/L1. MEDI1873 (GITR agonist) was proved to activate CD4+ $\mathrm{T}$ cell in peripheral blood and eliminate Treg intratumor (NCT02583165), while TRX518 (GITR agonist) is able to clear Treg cells but unable to reverse the deletion of
CD8+ T cells without combination with PD-1 antibody (NCT02628574). Wang et al. found that activating GITR combined with blocking PD1 can effectively reverse the depletion of CD8+ T cells and maintain the phenotype of memory $\mathrm{T}$ cells. The clearance of Treg by GITR antibody provided immune activation relief to CD8+ T cells, and the proliferation of CD8+ T cells intratumor was significant [73]. Results from ASCO 2018 meeting, revealed that under the condition of $170 \mathrm{mg}$ alone and $60 \mathrm{mg}$ in combination, MK-1248 (GITR agonist) had good tolerance, no dose-limiting toxicity and no treatment-related death for advanced solid cancer [74]. AS soon as combined with pembrolizumab, the therapeutic response was observed (1CR, 2PR; NCT02553499) (Fig. 1).

\section{Conclusion}

The rapid progression of immunotherapy in recent years has broken through the bottleneck of cytotoxicity-based chemotherapy in wild-type non-small cell lung cancer and improved the prognosis and life quality for patients. However, due to the little effective population of single drug treatment, the clinical application of ICIs is greatly limited. Synergistic effects in combination based on ICIs are expanding the beneficiary population. To be noticed, there are still lots of problems being eager to answers, such as the patient selection for best combination strategy, the identification of pseudoprogression, administration sequencing and so on. Moreover, combinations of PD-1/ L1 blockage and novel immune checkpoint inhibitor targeting other than PD-1/L1 axis are preliminary proved to be worth looking forward to overcome primary or adaptive resistance of anti-PD-1/L1 antibodies. Predictably, more novel agents and combination strategies will help to NSCLC treatment. However, how to achieve precise immunotherapy for maximizing the benefits of patients is worthy of our in-depth exploration in the future.

\section{Abbreviations \\ CTL: cytotoxic T lymphocyte; TPS: tumor proportion score; ALK: anaplastic lymphoma kinase; CNS: central nerve system; CPI: checkpoint inhibitor; DCR: disease control rate; EGFR: epidermal growth factor receptor; IgG1: immu- noglobulin G1; NSCLC: non-small cell lung cancer; ORR: objective response rate; OS: overall survival; PD-1/PD-L1: programmed cell death protein-1/ programmed cell death protein ligand-1; PFS: progression-free survival; TKI: tyrosine kinase inhibitor MPR: major pathological response; TMB: tumor muta- tion burden.}

\section{Acknowledgements}

Not applicable.

\section{Authors' contributions}

ZBQ and ZHC designed the outline, tables and drafted the manuscript. ZBQ and $C Z$ designed the figure. WZZ and CZ offered professional suggestions to the manuscript. All authors read and approved the final manuscript.

Funding

Not applicable. 
Availability of data and materials

Not applicable.

\section{Ethics approval and consent to participate}

Not applicable.

\section{Consent for publication}

Not applicable.

\section{Competing interests}

The authors declare that they have no competing interests.

Received: 27 June 2019 Accepted: 14 August 2019

Published online: 22 August 2019

\section{References}

1. Bray F, Ferlay J, Soerjomataram I, Siegel RL, Torre LA, Jemal A. Global cancer statistics 2018: GLOBOCAN estimates of incidence and mortality worldwide for 36 cancers in 185 countries. CA Cancer J Clin. 2018;68(6):394-424.

2. Schiller JH, Harrington D, Belani CP, Langer C, Sandler A, Krook J, Zhu J, Johnson $\mathrm{DH}$. Comparison of four chemotherapy regimens for advanced non-small-cell lung cancer. N Engl J Med. 2002;346(2):92-8.

3. Cafarotti S, Lococo F, Froesh P, Zappa F, Andre D. Target therapy in lung cancer. Adv Exp Med Biol. 2016;893:127-36.

4. Jing W, Li MM, Zhang Y, Teng FF, Han AQ, Kong L, Zhu H. PD-1/PD-L1 blockades in non-small-cell lung cancer therapy. OncoTargets Ther. 2016:9:489-502

5. Chen DS, Mellman I. Elements of cancer immunity and the cancerimmune set point. Nature. 2017;541(7637):321-30.

6. Chen DS, Mellman I. Oncology meets immunology: the cancer-immunity cycle. Immunity. 2013:39(1):1-10.

7. Boussiotis VA. Molecular and biochemical aspects of the PD-1 checkpoint pathway. N Engl J Med. 2016;375(18):1767-78.

8. Forde PM, Chaft JE, Smith KN, Anagnostou V, Cottrell TR, Hellmann MD, Zahurak M, Yang SC, Jones DR, Broderick S, et al. Neoadjuvant PD-1 blockade in resectable lung cancer. N Engl J Med. 2018;378(21):1976-86.

9. Garon EB, Rizvi NA, Hui R, Leighl N, Balmanoukian AS, Eder JP, Patnaik A, Aggarwal C, Gubens M, Horn L, et al. Pembrolizumab for the treatment of non-small-cell lung cancer. N Engl J Med. 2015;372(21):2018-28.

10. Herbst RS, Baas P, Kim DW, Felip E, Perez-Gracia JL, Han JY, Molina J, Kim JH, Arvis CD, Ahn MJ, et al. Pembrolizumab versus docetaxel for previously treated, PD-L1-positive, advanced non-small-cell lung cancer (KEYNOTE-010): a randomised controlled trial. Lancet (London, England). 2016;387(10027):1540-50.

11. Horn L, Spigel DR, Vokes EE, Holgado E, Ready N, Steins M, Poddubskaya E, Borghaei H, Felip E, Paz-Ares L, et al. Nivolumab versus docetaxel in previously treated patients with advanced non-small-cell lung cancer: two-year outcomes from two randomized, open-label, phase III trials (CheckMate 017 and CheckMate 057). J Clin Oncol. 2017:35(35):3924-33.

12. Rittmeyer A, Barlesi F, Waterkamp D, Park K, Ciardiello F, von Pawel J, Gadgeel SM, Hida T, Kowalski DM, Dols MC, et al. Atezolizumab versus docetaxel in patients with previously treated non-small-cell lung cancer (OAK): a phase 3, open-label, multicentre randomised controlled trial. Lancet (London, England). 2017;389(10066):255-65.

13. Gettinger $S$, Horn L, Jackman D, Spigel D, Antonia S, Hellmann M, Powderly J, Heist R, Sequist LV, Smith DC, et al. Five-year follow-up of nivolumab in previously treated advanced non-small-cell lung cancer: results from the CA209-003 study. J Clin Oncol. 2018:36(17):1675-84.

14. Ribas A. Adaptive immune resistance: how cancer protects from immune attack. Cancer Discov. 2015:5(9):915-9.

15. Koyama S, Akbay EA, Li YY, Herter-Sprie GS, Buczkowski KA, Richards WG, Gandhi L, Redig AJ, Rodig SJ, Asahina H, et al. Adaptive resistance to therapeutic PD-1 blockade is associated with upregulation of alternative immune checkpoints. Nat Commun. 2016;7:10501.

16. Antonioli L, Yegutkin GG, Pacher P, Blandizzi C, Hasko G. Anti-CD73 in cancer immunotherapy: awakening new opportunities. Trends Cancer. 2016;2(2):95-109.
17. André $P$, Denis $C$, Soulas $C$, Bourbon-Caillet $C$, Lopez J, Arnoux T, Blery M, Bonnafous C, Gauthier L, Morel A, Rossi B, Remark R, Breso V, Bonnet E, Habif G, Guia S, Ines Lalanne A, Hoffmann C, Lantz O, Vivier E. Anti-NKG2A $\mathrm{mAb}$ is a checkpoint inhibitor that promotes anti-tumor immunity by unleashing both T and NK cells. Cell. 2018. https://doi.org/10.1016/j. cell.2018.10.014 (ISBN: 0092-8674)

18. Durham NM, Holoweckyj N, MacGill RS, McGlinchey K, Leow CC, Robbins SH. GITR ligand fusion protein agonist enhances the tumor antigenspecific CD8 T-cell response and leads to long-lasting memory. J Immunother Cancer. 2017;5:47.

19. MokTSK, Wu YL, Kudaba I, Kowalski DM, Cho BC, Turna HZ, Castro G Jr, Srimuninnimit V, Laktionov KK, Bondarenko I, et al. Pembrolizumab versus chemotherapy for previously untreated, PD-L1-expressing, locally advanced or metastatic non-small-cell lung cancer (KEYNOTE-042): a randomised, open-label, controlled, phase 3 trial. Lancet (London, England). 2019:393(10183):1819-30.

20. Reck M, Rodriguez-Abreu D, Robinson AG, Hui R, Csoszi T, Fulop A, Gottfried M, Peled N, Tafreshi A, Cuffe S, et al. Pembrolizumab versus chemotherapy for PD-L1-positive non-small-cell lung cancer. N Engl J Med. 2016;375(19):1823-33.

21. Malhotra J, Jabbour SK, Aisner J. Current state of immunotherapy for nonsmall cell lung cancer. Transl Lung Cancer Res. 2017;6(2):196-211.

22. Tseng Chih-Wen, Hung Chien-Fu, Alvarez RD, Trimble C, Huh W, Kim D, Chuang CM, Lin CT, Tsai YC, He L, Monie A, Wu TC. Pretreatment with cisplatin enhances E7-specific CD8+ T-cell-mediated antitumor immunity induced by DNA vaccination. Clin Cancer Res. 2008;14:3185-92. https:// doi.org/10.1158/1078-0432.CCR-08-0037 (ISBN: 1078-0432)

23. Langer CJ, Gadgeel SM, Borghaei H, Papadimitrakopoulou VA, Patnaik A, Powell SF, Gentzler RD, Martins RG, Stevenson JP, Jalal SI, et al. Carboplatin and pemetrexed with or without pembrolizumab for advanced, nonsquamous non-small-cell lung cancer: a randomised, phase 2 cohort of the open-label KEYNOTE-021 study. Lancet Oncol. 2016;17(11):1497-508.

24. Paz-Ares L, Luft A, Vicente D, Tafreshi A, Gumus M, Mazieres J, Hermes B, Cay Senler F, Csoszi T, Fulop A, et al. Pembrolizumab plus chemotherapy for squamous non-small-cell lung cancer. N Engl J Med. 2018;379(21):2040-51.

25. Gandhi L, Rodriguez-Abreu D, Gadgeel S, Esteban E, Felip E, De Angelis F, Domine M, Clingan P, Hochmair MJ, Powell SF, et al. Pembrolizumab plus chemotherapy in metastatic non-small-cell lung cancer. N Engl J Med. 2018;378(22):2078-92.

26. Insinga RP, Vanness DJ, Feliciano JL, Vandormael K, Traore S, Burke T. Costeffectiveness of pembrolizumab in combination with chemotherapy in the 1 st line treatment of non-squamous NSCLC in the US. J Med Econ. 2018:21(12):1191-205.

27. Barlesi F, Nishio M, Cobo Manuel, Steele N, Paramonov V, Parente Barbara, Dear R, Berard H, Peled N, Seneviratne LC, Baldini E, Watanabe S, Goto K, Mendus D, Patel H, Deng Y, Kowanetz M, Hoang T, Lin W, Papadimitrakopoulou AV. LBA54IMpower132: efficacy of atezolizumab (atezo) + carboplatin (carbo)/cisplatin (cis) + pemetrexed (pem) as $1 \mathrm{~L}$ treatment in key subgroups with stage IV non-squamous non-small cell lung cancer (NSCLC). Ann Oncol. 2018. https://doi.org/10.1093/annonc/mdy424.066.

28. Jotte RM, Cappuzzo F, Vynnychenko I, Stroyakovskiy D, Abreu DR, Hussein MA, Soo RA, Conter HJ, Kozuki T, Silva C, Graupner V, Sun S, Lin SR, Kelsch C, Kowanetz M, Hoang T, Sandler A, Socinski M. IMpower131: primary PFS and safety analysis of a randomized phase III study of atezolizumab + carboplatin + paclitaxel or nab-paclitaxel vs carboplatin + nabpaclitaxel as $1 \mathrm{~L}$ therapy in advanced squamous NSCLC. J Clin Oncol. 2018;36:LBA9000. https://doi.org/10.1200/jco.2018.36.18_suppl.lba9000.

29. Borghaei H, Hellmann MD, Paz-Ares LG, Ramalingam SS, Reck M, O'Byrne KJ, Bhagavatheeswaran P, Nathan FE, Brahmer J. Nivolumab (Nivo) + platinum-doublet chemotherapy (Chemo) vs chemo as first-line $(1 \mathrm{~L})$ treatment (Tx) for advanced non-small cell lung cancer (NSCLC) with. J Clin Oncol. 2018;36:9001. https://doi.org/10.1200/JCO.2018.36.15_suppl.9001.

30. Buchbinder EI, Desai A. CTLA-4 and PD-1 pathways: similarities, differences, and implications of their inhibition. Am J Clin Oncol. 2016:39(1):98-106.

31. Hellmann MD, Rizvi NA, Goldman JW, Gettinger SN, Borghaei H, Brahmer $J R$, Ready NE, Gerber DE, Chow LQ, Juergens RA, et al. Nivolumab plus ipilimumab as first-line treatment for advanced non-small-cell lung cancer (CheckMate 012): results of an open-label, phase 1, multicohort study. Lancet Oncol. 2017;18(1):31-41. 
32. Reck M, Hellmann MD, Paz-Ares LG, Ramalingam SS, Brahmer JR, O'Byrne KJ, Bhagavatheeswaran P, Nathan FE, Borghaei H. Nivolumab (Nivo) + ipilimumab (Ipi) vs platinum-doublet chemotherapy (Chemo) as first-line (1L) treatment (TX) for advanced non-small cell lung cancer (NSCLC): safety analysis and patient-reported outcomes (PROs) From CheckMate 227. J Clin Oncol. 2018;36:9020. https://doi.org/10.1200/JCO.2018.36.15_ suppl.9020.

33. Ready N, Hellmann MD, Awad MM, Otterson GA, Gutierrez M, Gainor JF, Borghaei H, Jolivet J, Horn L, Mates M, et al. First-line nivolumab plus ipilimumab in advanced non-small-cell lung cancer (CheckMate 568): outcomes by programmed death ligand 1 and tumor mutational burden as biomarkers. J Clin Oncol. 2019;37(12):992-1000.

34. Antonia SJ, Brahmer JR, Khleif S, et al. Phase 1/2 study of the safety and clinical activity of durvalumab in patients with non-small cell lung cancer (NSCLC). Ann Oncol. 2016;27(Supplement 6):vi416-54. https://doi. org/10.1093/annonc/mdw383.16.

35. Antonia SJ, Kim SW, Spira IA, Ahn MJ, Ou SH, Stjepanovic N, Fasolo A, Jäger D, Ott PA, Wainberg AZ, Wakelee AH, Goldman W, Kurland J, Rebelatto CM, Yao W, Gupta KA, Blake-Haskins AJ, Segal HN. Safety and clinical activity of durvalumab (MEDI4736), an anti-PD-L1 antibody, in treatment-naïve patients with advanced non-small-cell lung cancer. J Clin Oncol. 2016;34:9029. https://doi.org/10.1200/JCO.2016.34.15_suppl .9029.

36. Papadimitrakopoulou V, Redman MW, Borghaei H, Wagar SN, Robert F, Kiefer GJ, McDonough S, Herbst RS, Kelly K, Gandara DR. 83OA phase II study of durvalumab (MEDI4736) for previously treated patients with stage IV squamous NSCLC (SqNSCLC): lung-MAP Sub-study SWOG S1400A. Jpn Soc Med Oncol. 2017. https://doi.org/10.1093/annonc/ $\mathrm{mdx091.003.}$

37. Garassino MC, Cho B-C, Kim J-H, et al. Durvalumab as third-line or later treatment for advanced non-small-cell lung cancer (ATLANTIC): an openlabel, single-arm, phase 2 study. Lancet Oncol. 2018;19(4):521-36.

38. Gulley $J$, et al. Avelumab for patients with previously treated metastatic or recurrent non-small-cell lung cancer (JAVELIN Solid Tumor): doseexpansion cohort of a multicentre, open-label, phase $1 \mathrm{~b}$ trial. Lancet Oncol. 2017;18(5):599-610.

39. Barlesi $F$, et al. Avelumab versus docetaxel in patients with platinum-treated advanced non-small-cell lung cancer (JAVELIN Lung 200): an open-label, randomised, phase 3 study. Lancet Oncol. 2018;19(11):1468-79.

40. Antonia S, Goldberg SB, Balmanoukian A, et al. Safety and antitumour activity of durvalumab plus tremelimumab in non-small cell lung cancer: a multicentre, phase 1b study. Lancet Oncol. 2016;17(3):299-308.

41. MokT, Schmid P, Arén O, et al. 192TiP: nEPTUNE: A global, phase 3 study of durvalumab (MEDI4736) plus tremelimumab combination therapy versus standard of care (SoC) platinum-based chemotherapy in the first-line treatment of patients (pts) with advanced or metastatic NSCLC. J Thorac Oncol Off Publ Int Assoc Study Lung Cancer. 2016;11 (4 Suppl):S140-1.

42. Reck M, Rodríguez-Abreu D, Robinson AG, et al. Pembrolizumab versus chemotherapy for PD-L1-positive non-small-cell lung cancer. N Engl J Med. 2016:375:1823.

43. Gandhi L, Rodriguez-Abreu D, et al. Pembrolizumab plus chemotherapy in metastatic non-small-cell lung cancer. N Engl J Med. 2018. https://doi. org/10.1056/nejmoa1801005.

44. Borghaei H, Paz-Ares L, Horn L, et al. Nivolumab versus docetaxel in advanced nonsquamous non-small-cell lung cancer. N Engl J Med. 2015;373(17):1627-39.

45. Tomasini $P$, Greillier L, Boyer A, Jeanson A, Barlesi F. Durvalumab after chemoradiotherapy in stage III non-small cell lung cancer. J Thorac Dis. 2018;10:S1032-6. https://doi.org/10.21037/jtd.2018.04.61.

46. Press Announcements: FDA expands approval of Imfinzi to reduce the risk of non-small cell lung cancer progressing; 2018. https://www.fda. gov/NewsEvents/Newsroom/PressAnnouncements/ucm597217.htm. Accessed 22 Feb 2018.

47. Yawn B, Wollan PC, Schroeder C, Gazzuola L, Mehta M. Temporal and gender-related trends in brain metastases from lung and breast cancer. Minnesota Med. 2004;86(12):32-7 (ISBN: 0026-556X).

48. Kim SY, Hong CK, Kim TH, Hong JB, Park CH, Chang YS, Kim HJ, Ahn CM, Byun MK. Efficacy of surgical treatment for brain metastasis in patients with non-small cell lung cancer. Yonsei Med J. 2015;56(1):103-11.
49. Dudnik E, Yust-Katz S, Nechushtan H, Goldstein DA, Zer A, Flex D, Siegal T, Peled N. Intracranial response to nivolumab in NSCLC patients with untreated or progressing CNS metastases. Lung cancer (Amsterdam, Netherlands). 2016;98:114-7.

50. Goldman JW, Crino L, Vokes EE, Holgado E, KL Reckamp, Płużański A, Spigel D, Kohlhaeufl M, Garassino M, Chow QML, Gettinger SN, Gerber DE, Havel L, Ramalingam SS, Dy GK, Geese WJ, Li A, Blackwood-Chirchir A, Healey DI, Brahmer J. Nivolumab (nivo) in patients (pts) with advanced (adv) NSCLC and central nervous system (CNS) metastases (mets). J Clin Oncol. 2016;34:9038. https://doi.org/10.1200/JCO.2016.34.15_suppl.9038.

51. Crino L, Bronte G, Bidoli P, Cravero P, Minenza E, Cortesi E, Garassino MC, Proto C, Cappuzzo F, Grossi F, et al. Nivolumab and brain metastases in patients with advanced non-squamous non-small cell lung cancer. Lung cancer (Amsterdam, Netherlands). 2019;129:35-40.

52. Goldberg SB, Gettinger SN, Mahajan A, Chiang AC, Herbst RS, Sznol M, Tsiouris AJ, Cohen J, Vortmeyer A, Jilaveanu L, et al. Pembrolizumab for patients with melanoma or non-small-cell lung cancer and untreated brain metastases: early analysis of a non-randomised, open-label, phase 2 trial. Lancet Oncol. 2016;17(7):976-83.

53. Brooks ED, Schoenhals JE, Tang C, Micevic G, Gomez DR, Chang JY, Welsh JW. Stereotactic ablative radiation therapy combined with immunotherapy for solid tumors. Cancer J (Sudbury, Mass). 2016;22(4):257-66.

54. Shaverdian N, Lisberg AE, Bornazyan K, Veruttipong D, Goldman JW, Formenti SC, Garon EB, Lee P. Previous radiotherapy and the clinical activity and toxicity of pembrolizumab in the treatment of non-small-cell lung cancer: a secondary analysis of the KEYNOTE-001 phase 1 trial. Lancet Oncol. 2017;18(7):895-903.

55. Antonia SJ, Villegas A, Daniel D, Vicente D, Murakami S, Hui R, Yokoi T, Chiappori A, Lee HK, Wit M, Cho CB, Bourhaba M, Quantin X, Tokito T, Mekhail T, Planchard D, Kim YC, Karapetis C, Hiret S, Özgüroğlu M. Durvalumab after chemoradiotherapy in stage III non-small-cell lung cancer. N Engl J Med. 2017. https://doi.org/10.1056/NEJMoa1709937.

56. Chen L, Douglass J, Kleinberg L, Ye X, Marciscano AE, Forde PM, Brahmer J, Lipson E, Sharfman W, Hammers H, et al. Concurrent immune checkpoint inhibitors and stereotactic radiosurgery for brain metastases in non-small cell lung cancer, melanoma, and renal cell carcinoma. Int J Radiat Oncol Biol Phys. 2018;100(4):916-25.

57. Ahmed KA, Kim S, Arrington J, Naghavi AO, Dilling TJ, Creelan BC, Antonia SJ, Caudell JJ, Harrison LB, Sahebjam S, et al. Outcomes targeting the PD-1/PD-L1 axis in conjunction with stereotactic radiation for patients with non-small cell lung cancer brain metastases. J Neurooncol. 2017;133(2):331-8

58. Hubbeling GH, Schapira E, Horick KN, Goodwin EHK, Lin JJ, Oh K, Shaw TA, Mehan AW, Shih AH, Gainor FJ. Safety of combined PD-1 pathway inhibition and intracranial radiation therapy in non-small cell lung cancer. J Thorac Oncol. 2018. https://doi.org/10.1016/j.jtho.2018.01.012 (ISBN: 1556-1380).

59. Colaco RJ, Martin P, Kluger HM, Yu JB, Chiang VL. Does immunotherapy increase the rate of radiation necrosis after radiosurgical treatment of brain metastases? J Neurosurg. 2016;125(1):17-23.

60. Ghanem S, El Bitar S, Hossri S, Weerasinghe C, Atallah JP. What we know about surgical therapy in early-stage non-small-cell lung cancer: a guide for the medical oncologist. Cancer Manag Res. 2017:9:267-78.

61. Liang Ying, Wakelee Heather. Adjuvant chemotherapy of completely resected early stage non-small cell lung cancer (NSCLC). Transl Lung Cancer Res. 2013;2:403-10. https://doi.org/10.3978/j.issn.22186751.2013.07.01 (ISBN: 2218-6751).

62. Group NM. Preoperative chemotherapy for non-small-cell lung cancer: a systematic review and meta-analysis of individual participant data. Lancet (London, England). 2014;383(9928):1561-71.

63. Xu YP, Li B, Xu XL, Mao WM. Is there a survival benefit in patients with stage IIIA (N2) non-small cell lung cancer receiving neoadjuvant chemotherapy and/or radiotherapy prior to surgical resection: a systematic review and meta-analysis. Medicine. 2015;94(23):e879.

64. Chaft JE, Forde PM, Smith KN, Anagnostou V, Cottrell T, Taube JM, Rekhtman N, Merghoub T, Jones DR, Hellmann MD, Yang SC, Broderick S, Rusch WV, Velculescu V, Topalian LS, Pardoll D, Brahmer J. Neoadjuvant nivolumab in early-stage, resectable non-small cell lung cancers. J Clin Oncol. 2017;35:8508. https://doi.org/10.1200/JCO.2017.35.15_suppl.8508.

65. Evangelista L, Cuppari L, Menis J, Bonanno L, Reccia P, Frega S, Pasello G. 18F-FDG PET/CT in non-small-cell lung cancer patients: a potential 
predictive biomarker of response to immunotherapy. Nuclear Med Commun. 2019:40:802-7.

66. Shu CA, Shu CA, Grigg C, Chiuzan C, Garofano RF, Patel V, Hernandez S, Negri T, Sacher AG, Smith-Marrone S, Stoopler M, Gainor JF, Awad MM, Ovidio F, Sonett RJ, Bacchetta M, Saqi A, Rizvi AN. Neoadjuvant atezolizumab + chemotherapy in resectable non-small cell lung cancer (NSCLC). J Clin Oncol. 2018;36:8532. https://doi.org/10.1200/ JCO.2018.36.15_suppl.8532.

67. Provencio-Pulla Mariano, Nadal Ernest, Cobo Manuel, Insa Amelia, Rivas Costa, Provencio-Pulla M, Nadal-Alforja E, Cobo M, Insa A, Costa Rivas M, Majem M, Rodriguez-Abreu D, Lopez-Vivanco G, Domine M, Del Barco Morillo E, Massuti B, Garcia-Campelo R, Marti MA, Bernabé R, Franco F, Jove M, Arrabal R, Martín P, Casal J, Calvo V. Neoadjuvant chemo/immunotherapy for the treatment of stages IIIA resectable non-small cell lung cancer (NSCLC): a phase II multicenter exploratory study-NADIM studySLCG. J Clin Oncol. 2018;36:8521. https://doi.org/10.1200/JCO.2018.36.15_ suppl.8521.

68. Cascone T, William NW, Weissferdt A, Leung HC, Federico L, Haymaker C, Bernatchez C, Fossella VF, Mott EF, Papadimitrakopoulou AV, Byers L, Lam KV, Godoy CM, Carter B, Lee JJ, Vaporciyan A, Gibbons D, Swisher GS, Heymach J, Sepesi B. LBA49Neoadjuvant nivolumab (N) or nivolumab plus ipilimumab (NI) for resectable non-small cell lung cancer (NSCLC). Ann Oncol. 2018. https://doi.org/10.1093/annonc/mdy424.059.

69. van Montfoort N, Borst L, Korrer MJ, Sluijter M, Marijt KA, Santegoets SJ, van Ham VJ, Ehsan I, Charoentong P, Andre P, et al. NKG2A blockade potentiates CD8 T cell immunity induced by cancer vaccines. Cell. 2018;175(7):1744-55.
70. Hay CM, Sult E, Huang Q, Mulgrew K, Fuhrmann SR, McGlinchey KA, Hammond SA, Rothstein R, Rios-Doria J, Poon E, et al. Targeting CD73 in the tumor microenvironment with MEDI9447. Oncoimmunology. 2016;5(8):e1208875.

71. Murtaza A, Laken H, Da Silva Correia J, McNeeley P, Altobell L, Zhang J, Vancutsem P, Wilcoxen K, Jenkins D. Discovery of TSR-022, a novel, potent anti-human TIM-3 therapeutic antibody. Eur J Cancer. 2016;69:S102. https ://doi.org/10.1016/S0959-8049(16)32903-3.

72. Riccardi C, Ronchetti S, Nocentini G. Glucocorticoid-induced TNFR-related gene (GITR) as a therapeutic target for immunotherapy. Expert Opin Ther Targets. 2018;22(9):783-97.

73. Wang B, Zhang W, Jankovic V, Golubov J, Poon P, Oswald EM, Gurer C, Wei J, Ramos I, Wu Q, et al. Combination cancer immunotherapy targeting PD-1 and GITR can rescue CD8(+) T cell dysfunction and maintain memory phenotype. Sci Immunol. 2018;3(29):eaat7061.

74. Geva Ravit, Voskoboynik Mark, Beebe AM, Gwo J, Dobrenkov K, Chartash E, Long GV. First-in-human phase 1 study of MK-1248, an anti-human glucocorticoid-induced tumor necrosis factor receptor (GITR) monoclonal antibody, as monotherapy or in combination with pembrolizumab in patients with advanced solid tumors. J Clin Oncol. 2018;36:3029. https:// doi.org/10.1200/JCO.2018.36.15_suppl.3029.

\section{Publisher's Note}

Springer Nature remains neutral with regard to jurisdictional claims in published maps and institutional affiliations.
Ready to submit your research? Choose BMC and benefit from:

- fast, convenient online submission

- thorough peer review by experienced researchers in your field

- rapid publication on acceptance

- support for research data, including large and complex data types

- gold Open Access which fosters wider collaboration and increased citations

- maximum visibility for your research: over $100 \mathrm{M}$ website views per year

At BMC, research is always in progress.

Learn more biomedcentral.com/submissions 